\title{
Current Practices in Prescribing Auto-Injectable Epinephrine during Immunotherapy amongst Otolaryngic Allergists
}

\author{
Kareem B. Haroun, Duncan C. Watley, Farrah N. Siddiqui* \\ Department of Otolaryngology, University of Texas Medical Branch, Galveston, TX, USA \\ Email: ^fnsiddiq@utmb.edu
}

How to cite this paper: Haroun, K.B., Watley, D.C. and Siddiqui, F.N. (2021) Current Practices in Prescribing Auto-Injectable Epinephrine during Immunotherapy amongst Otolaryngic Allergists. International Journal of Otolaryngology and Head \& Neck Surgery, 10, 258-267. https://doi.org/10.4236/ijohns.2021.104024

Received: April 27, 2021

Accepted: July 2, 2021

Published: July 5, 2021

Copyright $\odot 2021$ by author(s) and Scientific Research Publishing Inc. This work is licensed under the Creative Commons Attribution International License (CC BY 4.0).

http://creativecommons.org/licenses/by/4.0/

\begin{abstract}
Purpose: Allergen immunotherapy (AIT) while usually safe, is not without risk. Both sublingual (SLIT) and subcutaneous immunotherapy (SCIT) have the potential for systemic reactions including anaphylaxis. Materials and Methods: A short survey was distributed to fellows of the American Academy of Otolaryngic Allergy (AAOA) $(n=553)$ in July of 2019 to determine current prescribing practices. Results: A total of 103/553 surveys were completed, giving a response rate of $18.6 \%$. Prescribing patterns for SCIT showed $79.6 \%$ prescribed auto-injectable epinephrine (AIE) to all patients, $11.7 \%$ prescribed only to high risk patients, while $1.9 \%$ did not prescribe AIE at all. SLIT showed similar patterns with $71.8 \%$ prescribing AIE to all, $11.7 \%$ to high risk or letting patient choose, and $6.8 \%$ did not prescribe to anyone. Just under half of the physicians responded affirmatively to giving a written anaphylaxis plan to patients on immunotherapy. $48.5 \%$ physicians reported treating in-office anaphylaxis due to SCIT or skin testing in the past year, while $6 \%$ reported anaphylaxis due to SLIT. Conclusions: A majority of otolaryngic allergists are still prescribing AIE for both SCIT and SLIT. With the recent higher costs attributed to AIE as well as drug shortages, some physicians are risk-stratifying patients. While SCIT has a higher risk for treatment related systemic reactions, anaphylaxis does occur with SLIT, thus making it imperative to counsel patients on a clear anaphylaxis protocol in all forms of AIT.
\end{abstract}

\section{Keywords}

Allergy, Immunotherapy, Sublingual Immunotherapy, Subcutaneous Immunotherapy, Anaphylaxis, Epinephrine, Auto-Injectable Epinephrine

\section{Introduction}

The prevalence of allergic rhinitis (AR) is increasing globally, with more than 
one third of the population afflicted by at least one allergic disease in developed nations [1]. AR is projected to affect approximately 60 million people in the United States, with a prevalence of approximately $10 \%-30 \%$ in adults and up to $40 \%$ in children [2] [3] [4]. An analysis of US healthcare surveys in 2007 found AR to be the most common chronic disease in children in the United States [5]. AR is the fifth most common chronic disease in the United States overall [6]. AR is estimated to generate 2 - 5 billion dollars in direct health expenditures and an additional 2 - 4 billion in indirect cost through lost productivity annually [7] [8]. Treatment is important for both patient quality of life as well as productivity.

A variety of diagnostic tests and treatments are used in assisting patients in managing symptoms with significant variation in their use. Allergen-specific immunotherapy (AIT) is the only current treatment with disease-modifying effect for IgE-mediated allergic diseases [9]-[16]. Multiple systematic reviews have confirmed that subcutaneous immunotherapy (SCIT) and sublingual immunotherapy (SLIT) improve patient symptoms, decrease medication use, improve comorbid diseases such as asthma, and prevent new allergen sensitivities. The use of immunotherapy is not without potential adverse events. Reactions are generally classified as local or systemic. Local reaction can include induration and erythema (SCIT) and oral discomfort (SLIT). Systemic reactions vary significantly, but the feared adverse event is anaphylaxis [17] [18] [19] [20] [21].

The incidence of anaphylaxis during SCIT and SLIT administration has been well studied in the Otolaryngologic and Allergy/Immunology literature. This is highlighted well in the recent International Consensus Statement on Allergy and Rhinology: Allergic Rhinitis (ICAR) which aggregated all systematic reviews on both SCIT and SLIT finding only 7 reports of anaphylaxis requiring epinephrine administration when using SLIT, and no fatal anaphylactic events [18] [22] [23]. Further work has shown very low SLIT related anaphylaxis at 1 per 100 million doses or 1 per 526,000 treatment years, thus allowing SLIT to be administered at home and often utilized in patients with higher risk factors such as previous anaphylaxis to SCIT and asthma. Adverse reactions to SCIT are generally mild with $1.9 \%$ of patients experiencing a systemic reaction, only $0.08 \%$ and $0.02 \%$ having a WHO grade 3 or 4 reaction respectively [23] [24] [25]. Fatal anaphylaxis occurs in 1:2 - 2.5 million shot visits [26] [27].

Due to the relatively low rates of severe systemic reactions, the American Academy of Allergy, Asthma, and Immunology (AAAAI), American Academy of Otolaryngologic Allergy (AAOA), and the European Academy of Allergy and Clinical Immunology (EAACI) recommend risk-stratification, and permit physician discretion when prescribing epinephrine to patients on AIT [10] [28] [29].

Clinical practice has been evaluated on a small scale by previous survey studies. Specifically a study by P Gutpa et al. queried members of the AAAAI with 299 respondents showing a 33.3\% rate of epinephrine prescriptions for all patients on SCIT, $52.7 \%$ rate of risk stratification, and $13.5 \%$ rate of never prescribing epinephrine for SCIT. They found a large variation in practice pattern 
in terms of adhering to anaphylaxis action plans, occurrence of systemic reactions after leaving the office, and adherence to observation in clinic for $30 \mathrm{mi}$ nutes following injection [30]. Similar practice patterns have not been elucidated in the otolaryngologic allergy community.

With the advent of new sublingual tablets and biologic treatment options such as omalizumab, as well as the continued use of SCIT/SLIT, we sought to examine auto-injectable epinephrine (AIE) prescribing trends in patients being treated in otolaryngic allergy practices. This becomes even more pertinent due to the recent shortages and higher cost associated with AIEs.

\section{Methods}

A 10 question survey elucidating prescribing trends in auto-injectable epinephrine (AIE), provision of anaphylaxis action plans, and occurrence of anaphylaxis, was anonymously administered through SurveyMonkey to practicing fellows of the American Academy of Otolaryngic Allergy (AAOA) $(n=553)$ via the society list service in July of 2019. All analysis was performed on Microsoft Excel, version 16 (Microsoft Corp., Redmond, WA). This study was IRB exempt through the University of Texas Medical Branch.

The questions of the survey are listed here below:

1) Which of the following best describes your prescribing pattern for auto-injectable epinephrine to patients starting subcutaneous immunotherapy (SCIT)?

All patients prescribed auto-injectable epinephrine

No patients are prescribed auto-injectable epinephrine

Only high risk patients are prescribed auto-injectable epinephrine

Other (please specify)

2) Which of the following best describes your prescribing pattern for auto-injectable epinephrine in patients starting sublingual immunotherapy (drops or tablet)?

All patients prescribed auto-injectable epinephrine

No patients are prescribed auto-injectable epinephrine

Only high risk patients are prescribed auto-injectable epinephrine

Other (please specify)

3) Are you currently giving a written anaphylaxis action plan to all patients before starting subcutaneous immunotherapy (allergy shots)?

Yes

No

4) Are you currently giving a written anaphylaxis action plan to all patients starting sublingual immunotherapy (drops or tablet)?

Yes

No

5) Have you had any patients exhibit signs of anaphylaxis due to allergy shots or skin testing in your office in the last year? 
Yes

No

6) Can you estimate how many patients your practice has had to treat for in office anaphylaxis due to skin testing or allergy shots in the past one year?

0

1

$2-5$

$6-10$

$>10$

7) Have you ever had any patients exhibit signs of anaphylaxis due to sublingual immunotherapy (drops or tablet)?

Yes

No

8) Do you allow appropriate patients to perform SCIT at home?

Yes

No

Other (please specify)

9) If yes to number 8 , have any of your home SCIT patients had anaphylaxis due to allergy shots in the last year?

Yes

No

10) Do you or would you prescribe auto-injectable epinephrine to patients starting biologic medication such as omalizumab, mepolizumab or benralizumab?

Yes

No

\section{Results}

A total of 103/553 surveys were completed, giving a response rate of $18.6 \%$. All respondents were Otolaryngologists and practicing fellows of the American Academy of Otolaryngic Allergy (AAOA). Prescribing patterns for SCIT showed 79.6\% prescribed AIE to all patients, $11.7 \%$ prescribed only to high risk patients, while $1.9 \%$ did not prescribe AIE at all (Figure 1). SLIT showed similar patters with $71.8 \%$ prescribing AIE to all, $11.7 \%$ to high risk or letting patient choose, and $6.8 \%$ did not prescribe to anyone (Figure 2). $49.5 \%$ of physicians reported treating in-office anaphylaxis due to SCIT or skin testing in the past year, with the majority experiencing 1 case $(64.71 \%)$, and the remaining ranging from 2 - 5 cases (33.33\%). Only 6\% reported anaphylaxis due to SLIT (Figure 3). Just under half of the physicians responded affirmatively to giving a written anaphylaxis plan to patients on immunotherapy. $49.5 \%$ of respondents allowed at home SCIT use in appropriate patients resulting in 2 episodes of anaphylaxis at home during the past year. $59.8 \%$ of respondents additionally either prescribed or would prescribe AIE when patients starting biologic medications (Table 1). 


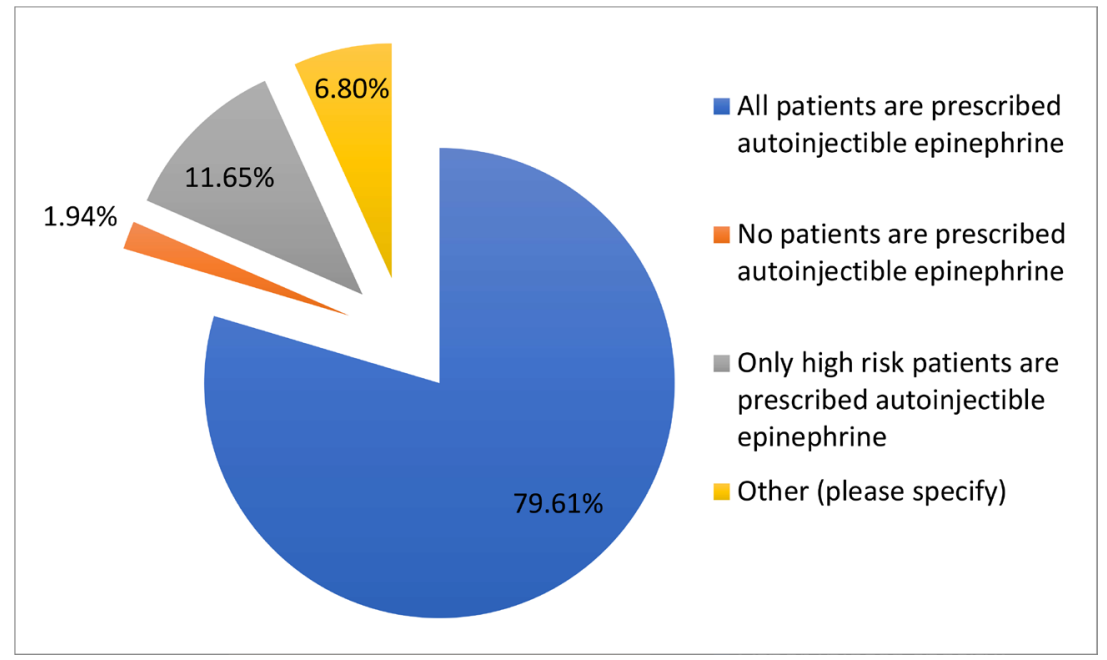

Figure 1. AIE prescription patterns for SCIT (Question 1).

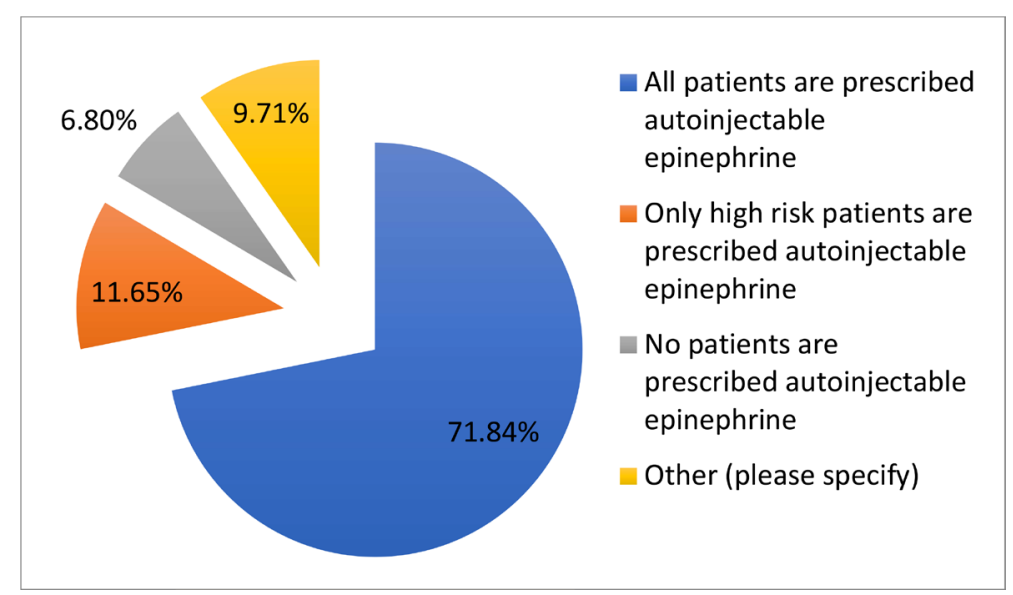

Figure 2. AIE prescription patterns for SLIT (Question 2).

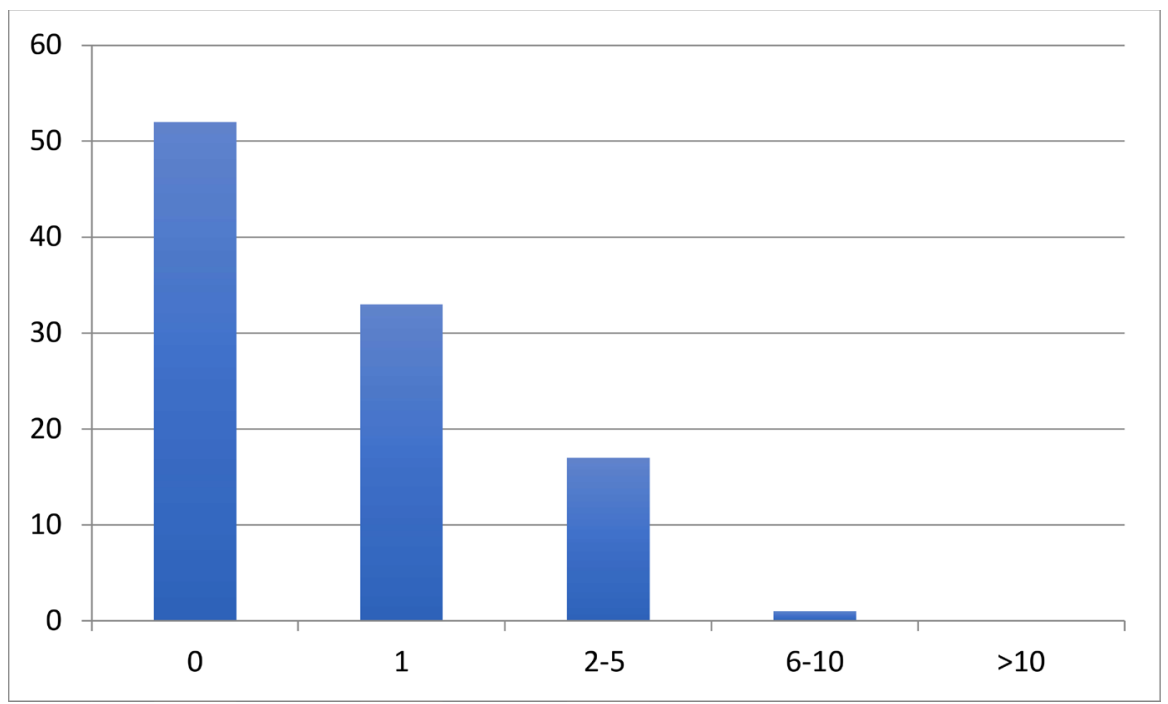

Figure 3. $\mathrm{X}$ axis: number of respondents, $\mathrm{Y}$ axis: number of patients experiencing in office anaphylaxis in office anaphylaxis in response to SCIT or allergy testing in the past 1 year. 
Table 1. Summary of remaining survey questions $3-10$.

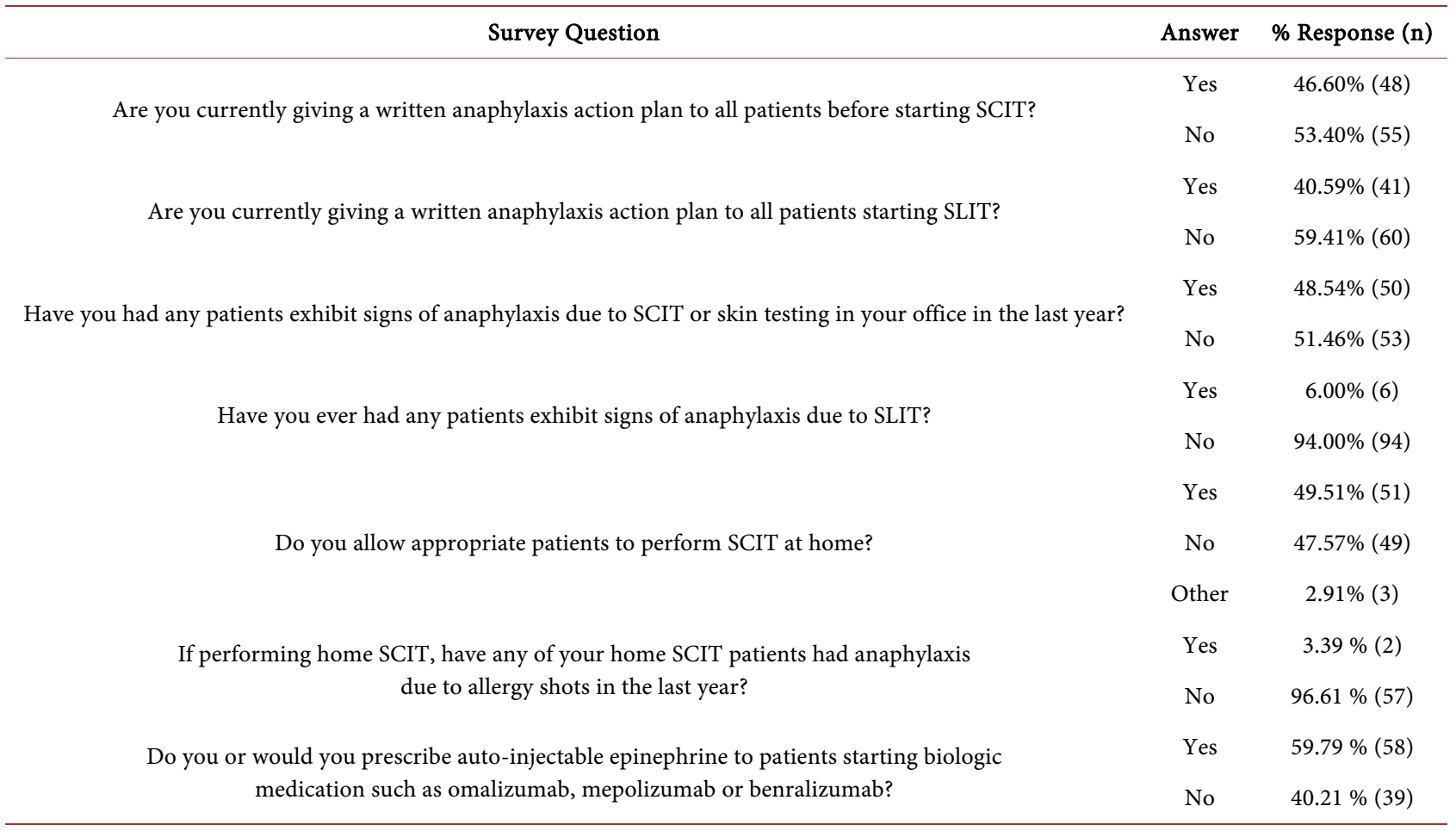

\section{Discussion}

As the disease burden from allergic rhinitis and asthma grows worldwide, safe and effective use of novel treatments such as SCIT, SLIT, sublingual tablet therapy, and biologics has become even more imperative [31]. All of these treatment approaches have an inherent risk for systemic reactions. Epinephrine is the treatment of choice in allergy emergencies [32] [33]. Multiple studies have shown that delayed epinephrine administration, or no epinephrine administration, increases the severity of systemic reactions, including increased fatality. Amin HS et al. found greater than a 20-minute delay in epinephrine administration in $30 \%$ of fatal anaphylactic reactions [34].

Our survey found significant differences in AIE prescription rates in Otolaryngology Allergy physicians compared with previous studies examining AAAAI physicians [30]. We showed a high rate of AIE prescription for both SCIT and SLIT patients. Allergy practice guidelines uniformly give recommendations to provide education and written anaphylaxis action plans prior to initiation of immunotherapy. Our survey found only $46.6 \%$ and $40.6 \%$ of respondents provided written anaphylaxis plans to SCIT and SLIT patients respectively. Without formal education regarding symptoms of anaphylaxis, and a clear plan of action, these symptoms can progress to near fatal or fatal systemic reactions. This point indicates a need for stronger practice guidelines and stricter physician adherence to them, especially in patients performing at home SCIT.

Many variables may determine the prescription pattern of AIE during allergy immunotherapy, including treatment risk, as well as cost and availability of epi- 
nephrine [35]. Although physician discretion is currently practiced in the prescription of AIEs for AIT, guidelines recommend caution and appropriate risk-stratification [10] [28] [29]. Patients at higher risk for systemic reactions include those with previous reaction to immunotherapy, poorly controlled asthma, high sensitization, co-seasonal therapy, and those on escalation therapy [27] [36] [37]. Our survey, as seen in the literature, showed an overall lower rate of anaphylaxis related to SLIT as compared to SCIT (Table 1 and Figure 3), thus justifying the lower AIE prescription rate for SLIT [18] [23]. SLIT may be a better option in high risk patients. It is safe to conclude that prescribing AIEs should be done in higher risk patients on AIT; low risk patients should at least receive counseling on signs and symptoms of systemic reactions including anaphylaxis and the ultimate decision can be based on shared decision-making.

Cost and availability of AIE continue to affect prescribing patterns in the United States. The major brand used in the United States has risen in price from less than $\$ 100$ dollars in 2007 to over $\$ 700$ in 2020 [38]. The generic version of the auto-injector kit was released in 2016, but supply of this product has been inconsistent across the country. Many patients in our practice are unable to obtain this product without notifying the pharmacy weeks in advance. This point further reinforces that patients at low risk of systemic reaction may not need to purchase the device. This could include patients on SLIT and patients on maintenance SCIT with no previous systemic reactions.

As with all survey-based studies, this study was limited by selection and response bias in respondents. To maintain anonymity and to keep the survey simple, socio-demographic characteristics of respondents were not collected.

\section{Conflicts of Interest}

The authors declare no conflicts of interest regarding the publication of this paper.

\section{References}

[1] Blomme, K., Tomassen, P., Lapeere, H., et al. (2013) Prevalence of Allergic Sensitization versus Allergic Rhinitis Symptoms in an Unselected Population. International Archives of Allergy and Immunology, 160, 200-207. https://doi.org/10.1159/000339853

[2] Berger, W.E. (2004) Allergic Rhinitis in Children: Diagnosis and Management Strategies. Pediatric Drugs, 6, 233-250. https://doi.org/10.2165/00148581-200406040-00003

[3] Nathan, R.A. (2007) The Burden of Allergic Rhinitis. Allergy \& Asthma Proceedings, 28, 3-9. https://doi.org/10.2500/aap.2007.28.2934

[4] Settipane, R.A. (2003) Rhinitis: A Dose of Epidemiological Reality. Allergy \& Asthma Proceedings, 24, 147-154.

[5] Mattos, J.L., Woodard, C.R. and Payne, S.C. (2011) Trends in Common Rhinologic Illnesses: Analysis of U.S. Healthcare Surveys 1995-2007. International Forum of Allergy \& Rhinology, 1, 3-12. https://doi.org/10.1002/alr.20003

[6] Bernstein, J.A. (2010) Allergic and Mixed Rhinitis: Epidemiology and Natural His- 
tory. Allergy \& Asthma Proceedings, 31, 365-369.

https://doi.org/10.2500/aap.2010.31.3380

[7] Meltzer, E.O. and Bukstein, D.A. (2011) The Economic Impact of Allergic Rhinitis and Current Guidelines for Treatment. Annals of Allergy, Asthma \& Immunology, 106, S12-S16. https://doi.org/10.1016/j.anai.2010.10.014

[8] Blaiss, M.S. (2010) Allergic Rhinitis: Direct and Indirect Costs. Allergy \& Asthma Proceedings, 31, 375-380. https://doi.org/10.2500/aap.2010.31.3329

[9] Pawankar, R., Canonica, G.W., Holgate, S., Lockey, R. and Blaiss, M. (2011) WAO White Book on Allergy. World Allergy Organization, Milwaukee.

[10] Roberts, G., Pfaar, O., Akdis, C.A., et al. (2018) EAACI Guidelines on Allergen Immunotherapy: Allergic Rhinoconjunctivitis. Allergy, 73, 765-798. https://doi.org/10.1111/all.13317

[11] Pajno, G.B., Fernandez-Rivas, M., Arasi, S., et al. (2018) EAACI Guidelines on Allergen Immunotherapy: IgE-Mediated Food Allergy. Allergy, 73, 799-815. https://doi.org/10.1111/all.13319

[12] Halken, S., Larenas-Linnemann, D., Roberts, G., et al. (2017) EAACI Guidelines on Allergen Immunotherapy: Prevention of Allergy. Pediatric Allergy and Immunology, 28, 728-745. https://doi.org/10.1111/pai.12807

[13] Dhami, S., Nurmatov, U., Arasi, S., et al. (2017) Allergen Immunotherapy for Allergic Rhinoconjunctivitis: A Systematic Review and Meta-Analysis. Allergy, 72, 1597-1631. https://doi.org/10.1111/all.13201

[14] Nurmatov, U., Dhami, S., Arasi, S., et al. (2017) Allergen Immunotherapy for IgE-Mediated Food Allergy: A Systematic Review and Meta-Analysis. Allergy, 72, 1133-1147. https://doi.org/10.1111/all.13124

[15] Kristiansen, M., Dhami, S., Netuveli, G., et al. (2017) Allergen Immunotherapy for the Prevention of Allergy: A Systematic Review and Meta-Analysis. Pediatric Allergy and Immunology, 28, 18-29. https://doi.org/10.1111/pai.12661

[16] Sturm, G.J., Varga, E.-M., Roberts, G., et al. (2018) EAACI Guidelines on Allergen Immunotherapy: Hymenoptera Venom Allergy. Allergy, 73, 744-764.

https://doi.org/10.1111/all.13262

[17] Calderon, M.A., Alves, B., Jacobson, M., Hurwitz, B., Sheikh, A. and Durham, S. (2007) Allergen Injection Immunotherapy for Seasonal Allergic Rhinitis. Cochrane Database of Systematic Reviews, No. 1, CD001936. https://doi.org/10.1002/14651858.CD001936.pub2

[18] Lin, S.Y., Erekosima, N., Kim, J.M., et al. (2013) Sublingual Immunotherapy for the Treatment of Allergic Rhinoconjunctivitis and Asthma: A Systematic Review. JAMA, 309, 1278-1288. https://doi.org/10.1001/jama.2013.2049

[19] Erekosima, N., Suarez-Cuervo, C., Ramanathan, M., et al. (2014) Effectiveness of Subcutaneous Immunotherapy for Allergic Rhinoconjunctivitis and Asthma: A Systematic Review. The Laryngoscope, 124, 616-627. https://doi.org/10.1002/lary.24295

[20] Marogna, M., Tomassetti, D., Bernasconi, A., et al. (2008) Preventive Effects of Sublingual Immunotherapy in Childhood: An Open Randomized Controlled Study. Annals of Allergy, Asthma \& Immunology, 101, 206-211.

https://doi.org/10.1016/S1081-1206(10)60211-6

[21] La Rosa, M., Ranno, C., André, C., Carat, F., Tosca, M.A. and Canonica, G.W. (1999) Double-Blind Placebo-Controlled Evaluation of Sublingual-Swallow Immunotherapy with Standardized Parietaria judaica Extract in Children with Allergic 
Rhinoconjunctivitis. The Journal of Allergy and Clinical Immunology, 104, 425-432. https://doi.org/10.1016/S0091-6749(99)70388-X

[22] Wise, S.K., Lin, S.Y., Toskala, E., et al. (2018) International Consensus Statement on Allergy and Rhinology: Allergic Rhinitis. International Forum of Allergy \& Rhinology, 8, 108-352. https://doi.org/10.1002/alr.22073

[23] Cox, L.S., Larenas Linnemann, D., Nolte, H., Weldon, D., Finegold, I. and Nelson, H.S. (2006) Sublingual Immunotherapy: A Comprehensive Review. The Journal of Allergy and Clinical Immunology, 117, 1021-1035. https://doi.org/10.1016/j.jaci.2006.02.040

[24] Epstein, T.G., Calabria, C., Cox, L.S. and Dreborg, S. (2017) Current Evidence on Safety and Practical Considerations for Administration of Sublingual Allergen Immunotherapy (SLIT) in the United States. The Journal of Allergy and Clinical Immunology: In Practice, 5, 34-40.e2. https://doi.org/10.1016/j.jaip.2016.09.017

[25] Epstein, T.G., Liss, G.M., Murphy-Berendts, K. and Bernstein, D.I. (2016) Risk Factors for Fatal and Nonfatal Reactions to Subcutaneous Immunotherapy: National Surveillance Study on Allergen Immunotherapy (2008-2013). Annals of Allergy, Asthma \& Immunology, 116, 354-359.e2. https://doi.org/10.1016/j.anai.2016.02.001

[26] Reid, M.J., Lockey, R.F., Turkeltaub, P.C. and Platts-Mills, T.A. (1993) Survey of Fatalities from Skin Testing and Immunotherapy 1985-1989. The Journal of Allergy and Clinical Immunology, 92, 6-15. https://doi.org/10.1016/0091-6749(93)90030-J

[27] Bernstein, D.I., Wanner, M., Borish, L., Liss, G.M., Immunotherapy Committee and American Academy of Allergy, Asthma and Immunology (2004) Twelve-Year Survey of Fatal Reactions to Allergen Injections and Skin Testing: 1990-2001. The Journal of Allergy and Clinical Immunology, 113, 1129-1136. https://doi.org/10.1016/j.jaci.2004.02.006

[28] Patel, A., Fisher, K., Fornadley, J., Wilson, K. and Iudenkova, O. (2015) American Academy of Otolaryngic Allergy Clinical Care Statements. http://www.aaoallergy.org/wp-content/uploads/2017/05/2015.Clinical-Care-Stateme nts-Bro.web .pdf

[29] Cox, L., Nelson, H., Lockey, R., et al. (2011) Allergen Immunotherapy: A Practice Parameter Third Update. The Journal of Allergy and Clinical Immunology, 127, S1-S55. https://doi.org/10.1016/j.jaci.2010.09.034

[30] Gupta, P., Gerrish, P.K., Silverman, B. and Schneider, A. (2012) Current Practices among Allergists on Writing Self-Injectable Epinephrine Prescriptions for Immunotherapy Patients. The Journal of Allergy and Clinical Immunology, 129, 571-572, 572.e1-2. https://doi.org/10.1016/j.jaci.2011.09.033

[31] Bousquet, J.J., Schünemann, H.J., Togias, A., et al. (2019) Next-Generation ARIA Care Pathways for Rhinitis and Asthma: A Model for Multimorbid Chronic Diseases. Clinical and Translational Allergy, 9, 44. https://doi.org/10.1186/s13601-019-0279-2

[32] Sampson, H.A., Muñoz-Furlong, A., Campbell, R.L., et al. (2006) Second Symposium on the Definition and Management of Anaphylaxis: Summary Report-Second National Institute of Allergy and Infectious Disease/Food Allergy and Anaphylaxis Network Symposium. The Journal of Allergy and Clinical Immunology, 117, 391-397. https://doi.org/10.1016/j.jaci.2005.12.1303

[33] Lieberman, P., Nicklas, R.A., Oppenheimer, J., et al. (2010) The Diagnosis and Management of Anaphylaxis Practice Parameter: 2010 Update. The Journal of Allergy and Clinical Immunology, 126, 477-480.e1-42. https://doi.org/10.1016/j.jaci.2010.06.022 
[34] Amin, H.S., Liss, G.M. and Bernstein, D.I. (2006) Evaluation of Near-Fatal Reactions to Allergen Immunotherapy Injections. The Journal of Allergy and Clinical Immunology, 117, 169-175. https://doi.org/10.1016/j.jaci.2005.10.010

[35] Sun, D., Cafone, J., Shaker, M. and Greenhawt, M. (2019) The Cost-Effectiveness of Requiring Universal vs Contextual Self-Injectable Epinephrine Autoinjector for Allergen Immunotherapy. Annals of Allergy, Asthma \& Immunology, 123, 582-589. https://doi.org/10.1016/j.anai.2019.09.009

[36] Simons, F.E.R., Ardusso, L.R.F., Dimov, V., et al. (2013) World Allergy Organization Anaphylaxis Guidelines: 2013 Update of the Evidence Base. International Archives of Allergy and Immunology, 162, 193-204. https://doi.org/10.1159/000354543

[37] Roy, S.R., Sigmon, J.R., Olivier, J., Moffitt, J.E., Brown, D.A. and Marshall, G.D. (2007) Increased Frequency of Large Local Reactions among Systemic Reactors during Subcutaneous Allergen Immunotherapy. Annals of Allergy, Asthma \& Immunology, 99, 82-86. https://doi.org/10.1016/S1081-1206(10)60626-6

[38] Kokosky, G. (2019) Newly Approved Generic Version of EpiPen Is Not Cheaper than Available Option: Teva's Epinephrine Injection May Not Undercut Mylan's on Price, But It Could Help in Addressing Shortages. Pharmacy Times, 85, 44. 